\title{
Molecular phylogeny of the Drosophila obscura species group, with emphasis on the Old World species Jian-jun Gao ${ }^{1,2}$, Hide-aki Watabe ${ }^{3}$, Tadashi Aotsuka4, Jun-feng Pang² and Ya- ping Zhang*1,2
}

Address: ${ }^{1}$ Laboratory for Conservation and Utilization of Bio-resources, Yunnan University, Kunming, Yunnan, China, ${ }^{2}$ State Key Laboratory of Genetic Resource and Evolution, Kunming Institute of Zoology, Chinese Academy of Sciences, Kunming, Yunnan, China, ${ }^{3}$ Biological Laboratory, Sapporo College, Hokkaido University of Education, Sapporo, Japan and ${ }^{4}$ Department of Biology, Tokyo Metropolitan University, Japan

Email: Jian-jun Gao - gao-leyun@263.net; Hide-aki Watabe - watabe@sap.hokkyodai.ac.jp; Tadashi Aotsuka - aotsuka-tadashi@c.metro-u.ac.jp; Jun-feng Pang - pangjfkiz@yahoo.com.cn; Ya-ping Zhang* - zhangyp1@263.net.cn

* Corresponding author

Published: 7 June 2007

BMC Evolutionary Biology 2007, 7:87 doi:10.1 186/147/-2/48-7-87

This article is available from: http://www.biomedcentral.com/I47/-2/48/7/87

(C) 2007 Gao et al; licensee BioMed Central Ltd.

This is an Open Access article distributed under the terms of the Creative Commons Attribution License (http://creativecommons.org/licenses/by/2.0), which permits unrestricted use, distribution, and reproduction in any medium, provided the original work is properly cited.
Received: 3 December 2006

Accepted: 7 June 2007

\begin{abstract}
Background: Species of the Drosophila obscura species group (e.g., D. pseudoobscura, D. subobscura) have served as favorable models in evolutionary studies since the 1930's. Despite numbers of studies conducted with varied types of data, the basal phylogeny in this group is still controversial, presumably owing to not only the hypothetical 'rapid radiation' history of this group, but also limited taxon sampling from the Old World (esp. the Oriental and Afrotropical regions). Here we reconstruct the phylogeny of this group by using sequence data from 6 loci of 21 species (including 16 Old World ones) covering all the 6 subgroups of this group, estimate the divergence times among lineages, and statistically test the 'rapid radiation' hypothesis.

Results: Phylogenetic analyses indicate that each of the subobscura, sinobscura, affinis, and pseudoobscura subgroups is monophyletic. The subobscura and microlabis subgroups form the basal clade in the obscura group. Partial species of the obscura subgroup (the $D$. ambigua/D. obscura/D. tristis triad plus the $D$. subsilvestris/D. dianensis pair) forms a monophyletic group which appears to be most closely related to the sinobscura subgroup. The remaining basal relationships in the obscura group are not resolved by the present study. Divergence times on a ML tree based on mtDNA data are estimated with a calibration of 30-35 Mya for the divergence between the obscura and melanogaster groups. The result suggests that at least half of the current major lineages of the obscura group originated by the mid-Miocene time ( 15 Mya), a time of the last developing and fragmentation of the temperate forest in North Hemisphere.
\end{abstract}

Conclusion: The obscura group began to diversify rapidly before invading into the New World. The subobscura and microlabis subgroups form the basal clade in this group. The obscura subgroup is paraphyletic. Partial members of this subgroup (D. ambigua, D. obscura, D. tristis, D. subsilvestris, and $D$. dianensis) form a monophyletic group which appears to be most closely related to the sinobscura subgroup. 


\section{Background}

Species of the Drosophila obscura group (41 species assigned to six subgroups) are mostly inhabitants of temperate forest throughout the Holarctic region, with some can adapted into high-elevation temperate-like habitats in the Afrotropical, Neotropical and Oriental regions. Some of these species (e.g., D. pseudoobscura and its close relatives) have served as favorable models for evolutionary biology since the influential works of Dobzhansky and his colleagues in the 1930's [1,2]. The whole-genome sequence of $D$. pseudoobscura was determined following $D$. melanogaster. Comparisons between the two species have shed new light on Drosophila genome evolution [3]. In addition, in the past two decades, increasing number of evolutionary studies have been conducted in a historical background of the obscura species group on varied subjects, e.g., evolution of genome size [4], evolution of karyotype and $P$ elements [5], origin and evolution of Drosophila Y chromosome [6] and genetics of morphological evolution [7].

Since the 1950's, a number of studies have been conducted to reconstruct phylogeny of the obscura group via a variety of approaches $[2,8]$. Recent molecular phylogenetic studies [9-13] clearly support the monophyly of the obscura species group and recover several well-supported lineages, for example, the affinis, pseudoobscura, and subobscura subgroups, the D. ambigua triad (D. obscura, D. ambigua and D. tristis), give essential support to the monophyletic origin of the New World species, i.e., those of the affinis and pseudoobscura subgroups. In spite of this, the relationship among the Old World obscura, subobscura, microlabis, and sinobscura subgroups, and their relationship to the New World clade are still poorly resolved. This phylogenetic predicament was partially ascribed to the "rapid radiation" history of the obscura group [10,12]. An alternative hypothesis to explain the lack of resolution at the base of this phylogeny is a bias in taxon sampling. For example, none of the previous phylogenetic studies has dealt with the obscura group as a whole: different studies employed different set of taxa, with species from the Afrotropical region (5 species) and Oriental region (8 described +2 undescribed species) have rarely been investigated $[14,15]$, probably due to the difficulty in collecting and/or culturing these poorly known taxa.

In the present study, nucleotide sequences (henceforth referred to as NT) from six loci (Table 1) of $21 \mathrm{D}$. obscura group species and $2 \mathrm{D}$. melanogaster group species (Table 2) are used to reconstruct the phylogeny of the obscura species group. Phylogenetic analyses are also performed based on translated amino acid sequences (henceforth referred to as AA). We then estimate the divergence times in the obscura group, and statistically test the previously
Table I: Gene loci sampled in the present study. Numbers show aligned lengths and numbers of parsimony informative sites (PI, given in parentheses) for nucleotide or translated amino acid sequences of each locus.

\begin{tabular}{lcc}
\hline Gene loci & $\begin{array}{c}\text { Nucleotide } \\
\text { sequences }\end{array}$ & $\begin{array}{c}\text { Translated amino } \\
\text { acid sequences }\end{array}$ \\
\hline $\begin{array}{l}\text { Mitochondrial genes } \\
\quad \text { NADH dehydrogenase subunit }\end{array}$ & $1029(292)$ & $342(69)$ \\
$\quad \begin{array}{l}\text { (ND2) } \\
\text { Cytochrome oxidase subunit I } \\
(\text { COI) }\end{array}$ & $496(127)$ & $158(3)$ \\
$\begin{array}{l}\text { Cytochrome oxidase subunit II } \\
\text { (COII) }\end{array}$ & $688(171)$ & $230(16)$ \\
$\begin{array}{l}\text { Cytochrome b (Cyt b) } \\
\text { Nuclear genes }\end{array}$ & $893(232)$ & $296(18)$ \\
$\quad \begin{array}{l}\text { Alcohol dehydrogenase (Adh) } \\
28 S \text { ribosomal RNA (28S) }\end{array}$ & $370(84)$ & $123(14)$ \\
Total & $650(33)$ & - \\
\hline
\end{tabular}

proposed "rapid radiation" hypothesis $[10,12]$. Finally, the evolutionary history of the obscura group is discussed.

\section{Results}

\section{Summary of the DNA sequences}

The alignment of the six gene regions spanned 4,126 nucleotide or 1,149 amino acid positions (Table 1). Table 3 gives accession numbers for the nucleotide sequences, either cited from GenBank [9-11,13,15-28] or newly determined for this study.

A plot of nucleotide substitution saturation is shown in Figure 1. For the mitochondrial sequences, the transition/ transversion (ti/tv) ratio in $1 \mathrm{st}+2 \mathrm{nd}$ codon positions (Figure $1 \mathrm{~A}$ ) ranges from 13.50 (D. ambigua vs. D. obscura) to 1.313 (D. dianensis vs. D. guanche), with the average of 2.70; and the ratio in the 3rd codon position (Figure 1B) ranges from 6.750 (D. pseudoobscura vs. D. miranda) to 0.581 (D. affinis vs. D. madeirensis), with the average of 1.08. This suggests strong saturation in the 3rd codon positions between distantly related species. For the Adh gene, the ti/tv ratio in $1 \mathrm{st}+2 \mathrm{nd}$ codon positions (Figure 1C) ranges from 3.00 (e.g., D. ambigua vs. D. guanche) to 0.00 (D. miranda vs. D. persimilis); the ratio in the 3rd codon positions ranges from 4.50 (D. limingi vs. D. tsukubaensis) to 0.429 (D. obscura vs. D. affinis/D. limingi). Slight decrease of $\mathrm{ti} / \mathrm{tv}$ is found in the 3rd codon positions with increase of pairwise distance.

\section{Pairwise partition homogeneity test (PHT)}

Table 4 shows the results of pairwise PHT between NT partitions. On a threshold of $P=0.05$ [29], incongruences are found in 4 out of 15 pairwise tests (ND2 vs. COI, ND2 vs. $A d h, C O I$ vs. COII, and COI vs. Adh) with un-weighted parsimony scheme. Compared to this, when a six-parameter weighting scheme (see below for details) was imple- 
Table 2: Species sampled in the present study and collection data of samples used for DNA sequencing.

\begin{tabular}{|c|c|c|c|}
\hline $\begin{array}{l}\text { Species } \\
\text { group }\end{array}$ & Species subgroup & Species & Geographical Origin \\
\hline \multirow[t]{22}{*}{ obscura } & affinis & affinis & Pennsylvania, USA* \\
\hline & & helvetica & $\begin{array}{l}\text { Unknown site, } \\
\text { Switzerland }\end{array}$ \\
\hline & pseudoobscura & pseudoobscura & California, USA* \\
\hline & & persimilis & Unknown site, USA* \\
\hline & & miranda & Unknown site, USA* \\
\hline & obscura & ambigua & Vienna, Austria \\
\hline & & obscura & Tuebingen, Germany \\
\hline & & tristis & Tuebingen, Germany \\
\hline & & subsilvestris & Tuebingen, Germany \\
\hline & & dianensis & $\begin{array}{l}\text { Kunming, Yunnan, } \\
\text { China }\end{array}$ \\
\hline & & bifasciata & $\begin{array}{l}\text { Yakutsuk, East Siberia, } \\
\text { Russia }\end{array}$ \\
\hline & & imaii & Sapporo, Japan \\
\hline & & limingi & $\begin{array}{l}\text { Kunming, Yunnan, } \\
\text { China }\end{array}$ \\
\hline & & tsukubaensis & Koganei, Tokyo, Japan \\
\hline & sinobscura & sinobscura & Chitou, Taiwan, China \\
\hline & & luguensis & $\begin{array}{l}\text { Lugu Lake Nature } \\
\text { Reserve, Yunnan, } \\
\text { China }\end{array}$ \\
\hline & & hubeiensis (HB) & $\begin{array}{l}\text { Shennongjia Nature } \\
\text { Reserve, Hubei, China }\end{array}$ \\
\hline & & hubeiensis (KM) & $\begin{array}{l}\text { Kunming, Yunnan, } \\
\text { China }\end{array}$ \\
\hline & subobscura & subobscura & Helsinki, Finland \\
\hline & & guanche & Canary Is. \\
\hline & & madeirensis & Madeira Is. \\
\hline & microlabis & microlabis & Mt. Elgon, Kenya \\
\hline \multirow[t]{2}{*}{$\begin{array}{l}\text { melano } \\
\text { gaster }\end{array}$} & melanogaster & melanogaster & $\begin{array}{l}\text { All sequences from } \\
\text { GenBank }\end{array}$ \\
\hline & & yakuba & $\begin{array}{l}\text { All sequences from } \\
\text { GenBank }\end{array}$ \\
\hline
\end{tabular}

* Stocks from the Bowling Green Stock Center, with missing stock numbers.

mented, the $P$ values for most pairwise comparisons increased greatly.

Incongruence between data partitions indicates that the two partitions compared have had different histories or that one of them violate the assumptions of the phylogenetic method [29]. The PHT is currently implemented with only parsimony, which assuming small number of actual sequence changes per site. Higher $P$ values obtained by six-parameter weighting may indicates that, the sixparameter parsimony method fits the NT data better by accounting for the effect of multiple hits (as suggested in the saturation plot in Figure 1), thus reduces the incongruence in several pairwise comparisons.

\section{Phylogenetic analyses with NT data}

Results of analyses with NT data using the maximum parsimony (MP), maximum likelihood (ML) and Bayesian inference (BI) methods are shown in Figure 2. These analyses lend strong support to the monophyly of the obscura group, recover the same set of major lineages in this group, including the affinis, pseudoobscura, subobscura and sinobscura subgroups, the D. ambigua triad (D. ambigua, D. obscura and D. tristis), and the D. dianensis/D. subsilvestris, D. bifasciata/D. imaii and D. limingi/D. tsukubaensis lineages, each supported with high bootstrap value (BP) or posterior probability (PP). All the trees strongly support the sister relationship between the affinis and pseudoobscura subgroups ( $\mathrm{BP}=94-97 ; \mathrm{PP}=1.00)$. They completely agree with each other with respect to relationship within each of the major lineages. The branching orders within the pseudoobscura and subobscura subgroups are largely consistent with those of previous studies. The order within the sinobscura subgroup is also suggested by data of morphology [30] or interspecific reproductive isolation (Gao et al., unpublished data).

The MP tree deduced with the un-weighted method (Figures $2 \mathrm{~A}$; henceforth referred to as uwMP tree) clusters the $D$. ambigua triad with the sinobscura subgroup, while puts the $D$. dianensis/D. subsilvestris pair outside this cluster. However, the MP tree deduced with the six-parameter weighting method (Figure 2B; henceforth referred to as $6 \mathrm{pMP}$ tree), the ML tree (Figure $2 \mathrm{C}$ ) and the Bayesian tree (Figure 2D) congruously suggest a cluster of the $D$. ambigua triad and the D. dianensis/D. subsilvestris pair. This cluster (henceforth referred to as obscura cluster) forms a larger cluster with the sinobscura subgroup (henceforth referred to as obscura-sinobscura cluster). However, the supports for these relationships are also low.

D. microlabis, as the single representative of the microlabis subgroup, is placed at the basal position in the uwMP and $6 \mathrm{pMP}$ trees. However, this species is clustered with the subobscura subgroup in the ML tree (Figure $2 \mathrm{C}, \mathrm{BP}=93$ ) and Bayesian tree (Figure 2D; $\mathrm{PP}=1.00$ ). The uwMP, $6 \mathrm{pMP}$ and Bayesian trees suggest weakly $(\mathrm{BP}=6-39 ; \mathrm{PP}=$ 0.81 ) a close relationship between the obscura-sinobscura cluster and the New World clade. However, the ML tree clusters all the Old World species into a large group with weak support $(\mathrm{BP}=28)$.

\section{Phylogenetic analyses with AA data set}

Figure 3 shows the results of phylogenetic analyses with AA data, including the strict consensus of 17 equally parsimonious MP trees (Figure $3 \mathrm{~A}$ ) and the Bayesian trees inferred with the Poisson model (Figure 3B) or the GTR (General time reversible) model (Figure 3C). All these trees recover the same set of major lineages as those trees of NT data, clearly indicating that the microlabis and subobscura subgroups are basal to the remainder ingroup species $(\mathrm{BP}=53 ; \mathrm{PP}=0.96-0.99)$, all of which form a very large monophyletic group. The Bayesian analyses strongly 
Table 3: Accession numbers for sequences. Sequences with underlined accession numbers are used for the statistical test of temporal pattern only.

\begin{tabular}{|c|c|c|c|c|c|c|}
\hline & ND2 & $\mathrm{COI}$ & COII & Cyt b & Adh & 285 \\
\hline D. luguensis & EF216229 & EF21 6247 & $\mathrm{EF} 216257$ & EF216273 & $E F 216308$ & EF2I6295 \\
\hline D. sinobscura & EF216236 & EF216249 & EF216259 & $E F 216280$ & U90954 [15] & EF216303 \\
\hline D. hubeiensis (HB) & $E F 216225$ & $E F 216243$ & $E F 216253$ & $E F 216269$ & U90953 [15] & EF21629I \\
\hline D. hubeiensis (KM) & $E F 216226$ & EF2 I 6244 & EF216254 & $E F 216270$ & $E F 216312$ & EF216292 \\
\hline D. dianensis & $E F 216222$ & $E F 21624 \mid$ & $E F 21625 I$ & $E F 216266$ & $E F 216310$ & EF2I6288 \\
\hline D. subsilvestris & $E F 216237$ & U51616 [1I] & $E F 216260$ & $E F 216281$ & AF067283 [27] & EF2I 6304 \\
\hline D. bifasciata & $E F 216221$ & U5I6II [II] & M95। 47 [9] & $E F 216265$ & U40986 [20] & EF2I6287 \\
\hline D. imaii & $E F 216227$ & $E F 216245$ & $E F 216255$ & EF2 I627I & U40987 [20] & EF216293 \\
\hline D. tsukubaensis & EF216239 & $E F 216250$ & $E F 216261$ & $E F 216283$ & AF067284 [27] & $E F 216306$ \\
\hline D. limingi & $E F 216228$ & EF216246 & $E F 216256$ & $E F 216272$ & EF216309 & EF216294 \\
\hline D. obscura & $E F 216233$ & U5I6I4 [1I] & AF08I356 [13] & EF2 I 6277 & U90955 [15] & EF216300 \\
\hline D. ambigua & EF216220 & U51610 [1I] & M95। 45 [9] & EF216264 & $X 54813[21]$ & $E F 216286$ \\
\hline D. tristis & $E F 216240$ & U51617 [1I] & EF216262 & $E F 216284$ & U90956 [15] & EF2I 6307 \\
\hline D. subobscura & $E F 216238$ & U5I6I5 [1I] & M95I5I [9] & EF216282 & M55545 [22] & EF2I6305 \\
\hline D. madeirensis & $E F 216230$ & U51613 [1I] & AF08I355 [I3] & EF2 I 6274 & X60II2 [23] & EF216296 \\
\hline D. guanche & $E F 216223$ & U51612 [1I] & AF08I354 [13] & $E F 216267$ & $\times 60113$ [23] & EF216289 \\
\hline D. affinis & $E F 216219$ & U5I604 [1I] & M95। 40 [9] & EF216263 & AF067280 [27] & EF2I 6285 \\
\hline D. algonquin & - & - & M95। 44 [9] & $\underline{\cup 07279}[10]$ & - & - \\
\hline D. athabasca & - & - & M95।4I [9] & - & - & - \\
\hline D. azteca & - & $\underline{\mathrm{U} 51605}$ [1I] & M95। 46 [9] & $\underline{U 07283}[10]$ & - & $\underline{X 7 \mid 205}[17]$ \\
\hline D. narragansett & - & - & M95।49 [9] & - & - & - \\
\hline D. tolteca & - & - & M95।52 [9] & - & AF081357 [13] & - \\
\hline D. helvetica & EF216224 & EF216242 & $E F 216252$ & EF216268 & AF067282 [27] & $E F 216290$ \\
\hline D. pseudoobscura & EF216235 & U5I602 [II] & M95।50 [9] & EF216279 & X68I64 [24] & EF216302 \\
\hline D. persimilis & $E F 216234$ & U5I609 [II] & M95। 43 [9] & $E F 216278$ & M60997 [25] & EF21630I \\
\hline D. miranda & EF216232 & U5I608 [1I] & M95। 48 [9] & EF216276 & M60998 [25] & EF216299 \\
\hline D. lowei & - & - & M95।42 [9] & - & - & - \\
\hline D. microlabis & EF21623I & $E F 216248$ & $E F 216258$ & EF216275 & EF21631I & $E F 216298$ \\
\hline D. melanogaster & NC_001709 [16] & U51619 [1I] & J01404 [19] & NC00I709 [16] & MI7833 [26] & EF216297 \\
\hline D. yakuba & X03240 [17] & X03240 [18] & X03240 [18] & X03240 [18] & $\times 54120^{*}$ & X7II67 [28] \\
\hline
\end{tabular}

* Ashburner, unpublished data.

indicate that $D$. microlabis forms a monophyletic group with the subobscura subgroup $(\mathrm{PP}=0.99)$. All the analyses with AA data lend strong support to the monophyly of the obscura cluster $(\mathrm{BP}=87 ; \mathrm{PP}=1.00)$, while the obscurasinobscura cluster is only weakly suggested by the Bayesian tree inferred with the Poisson model.

The Bayesian trees of $\mathrm{AA}$ data recover the same relationships within each of the major lineages as those of the NT data, except for that they suggest a branching order of (ambigua, (obscura, tristis)) in the D. ambigua triad, and that the tree inferred with the Poisson model clusters the Kunming (KM) strain of D. hubeiensis with D. sinobscura, instead of its conspecific Hubei (HB) strain. However, all these relationships are very weakly supported.

\section{Divergence times in the obscura species group}

The divergence times are estimated on a given tree - a ML tree constructed with the concatenated mitochondrial sequences. This tree is selected as a representative phylogenetic hypothesis of the obscura group based on the foregoing results. The results of time estimation are shown as a linearized form of the ML tree (Figure 4). In light of the upper bound (35 Mya) of the calibration time interval for the obscura-melanogaster divergence, the estimated time span for the major radiation of the obscura group is $\sim 14.9-$ 21.8 Mya, indicating that by the mid-Miocene time ( 15 Mya), almost all the current major lineages of the obscura group had come into being. Even in light of the calibration point of $30 \mathrm{Mya}$, at least half of the major lineages are estimated to have originated by the mid-Miocene time. The splitting between the D. ambigua triad and the D. dianensis/D. subsilvestris pair ( 14.9/12.9 Mya for upper/ lower bounds) falls close to the major radiation of the obscura group, and the splitting between $D$. limingi and $D$. tsukubaensis ( 13.0/11.2 Mya) appears to be rather old. The sinobscura subgroup began to diversify ( $\sim 2.99 / 2.57$ Mya) from about the mid-Pliocene time.

Our estimate for the origin of the microlabis-subobscura clade ( 19.5/16.7 Mya) falls close to previous estimation based on mutation distance of 11 genes $(17.7 \pm 4.4$ Mya; D. pseudoobscura vs. D. subobscura) [31]; the estimate for the splitting between the affinis-pseudoobscura clade and 


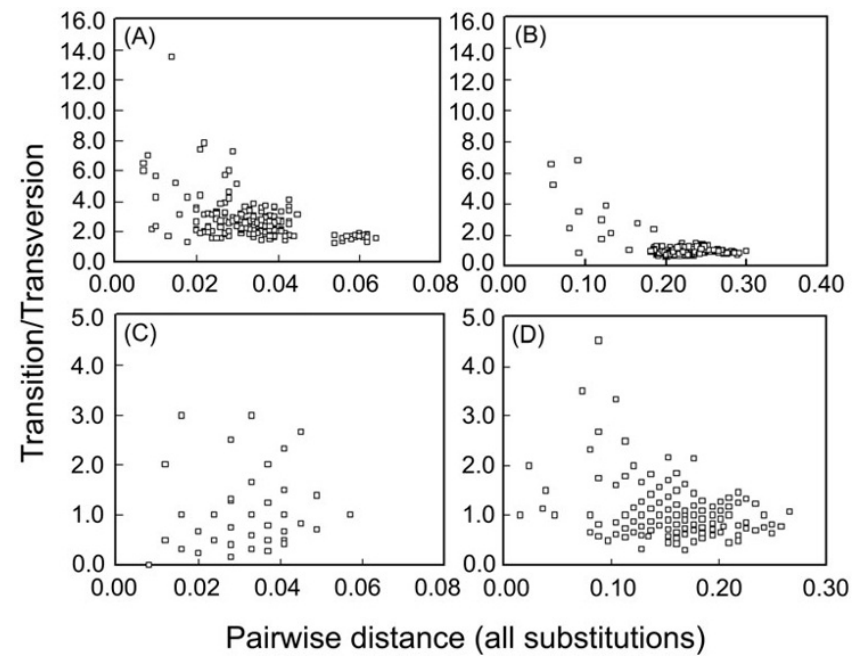

Figure I

Saturation plots for nucleotide substitutions. For each comparison, ratios of ti/tv for pairs of sequences ( $\mathrm{Y}$-coordinate) are graphed versus the corresponding numbers of total substitutions (X-coordinate). $(A)$ and $(B)$, concatenated sequence of the mitochondrial genes, Ist +2 nd and $3 \mathrm{rd}$ codon positions, respectively; (C) and (D), Adh sequence, Ist+2nd and $3 r d$ codon positions, respectively.

the obscura-sinobscura cluster ( 17.9/15.4 Mya) is clearly older than the previous one based on Adh sequences (13.1 \pm 1.74 Mya; obscura subgroup vs. pseudoobscura subgroup) [32], and the estimate for the D. pseudoobscura-D. miranda divergence (4.93/3.76 Mya) differs greatly from the estimate based on mutation distances $(2.00 \pm 0.6 \mathrm{Mya})$ [31]. This is mainly due to that 1 ) our estimates is not directly based on pairwise distances, but on a given tree with branch lengths; 2 ) we use different calibration point from those studies [31,32].

\section{Statistic test of the temporal pattern of evolutionary diversity}

To test the temporal pattern of the evolution of the obscura group, an empirical tree of 27 obscura group species (a

Table 4: Results of pairwise partition homogeneity test (PHT). Numbers above and below diagonal show $P$-values resulted of the un-weighted and the six-parameter weighting methods, respectively.

\begin{tabular}{lcccccc}
\hline & ND2 & COI & COII & Cyt b & Adh & $28 S$ \\
\hline ND2 & & $0.026^{*}$ & 0.079 & 0.353 & $0.010^{*}$ & 0.925 \\
COI & 0.082 & & $0.012^{*}$ & 0.083 & $0.005^{*}$ & 0.984 \\
COII & 0.346 & 0.135 & & 0.354 & 0.142 & 0.855 \\
Cyt b & 0.196 & 0.118 & 0.365 & & 0.149 & 0.996 \\
Adh & 0.187 & 0.076 & 0.297 & 0.202 & & 0.892 \\
28S & 0.938 & 0.984 & 0.988 & 0.956 & 0.843 & \\
\hline
\end{tabular}

KITSCH tree; not shown) is constructed under an assumption of molecular clock, therefore all the terminal taxa on this tree are shown as contemporaneous. The cumulative frequency distribution (CFD) of the branching times (after normalization) along this tree is plotted (Figure 5). An "expected" CFD for 27-taxa trees is provided as contrast. This expected CFD, available from Wollenberg et al [33], is the average of five hundred 27-taxa trees generated by computer simulation under null model of stochastic speciation/extinction. The comparison between the empirical and average CFDs with the Kolmogorov-Smirnov (K-S) test [34] results a K-S $D$ value of 0.4975 . The $P$ value associated with this $D$ value is very low $(P<0.0004$, significant), therefore rejected the null hypothesis [33], indicating that the branching pattern in the KITSCH tree differs from the expected stochastic timing of speciation/ extinction [33]. It is clearly seen that the CFD of the KITSCH tree begins to deflect upwards from the average CFD at a relative early stage of the branching process, suggesting an ancient cluster of branching events during the evolutionary history of the obscura group.

\section{Discussion}

\section{Phylogenetic relationship in the obscura group}

Phylogeny of the obscura species group is investigated with dense taxon-sampling from the Old World, especially the Oriental region, using both nucleotide and translated amino acid sequences of multiple loci. The results corroborate some previously well-recognized relationships, and shed some new light on the evolutionary history of the obscura group, especially the relationship among major lineages.

The MP trees of NT data suggest with low confidence that D. microlabis alone, as a long-branch taxon, represents the first branch in the obscura group. However, it was strongly suggested in the ML tree (Figure $2 \mathrm{C}$ ) and Bayesian trees (Figures 2D, 3B, and 3C) that D. microlabis forms a monophyletic group with the subobscura subgroup. A suspicion arises whether the basal position of D. microlabis is true, or an artifact due to long-branch attraction (LBA) by those outgroups? As demonstrated by Anderson and Swofford [35], if this relationship is true, MP method is prone to positively recover it, thus seems to perform as good as, or even better than ML method. Otherwise, ML will outperform MP by recovering the true relationship. As shown by some studies with empirical data and/or computer simulation [35-37], model-based methods (ML and Bayesian methods) can be relatively robust against branch-length differences, even against model violation. Therefore, it is very likely that the basal relationship of $D$. microlabis alone in the MP trees is an artifact due to LBA, while the $\mathrm{ML}$ and Bayesian trees suggest the true relationship between the microlabis and subobscura subgroups. 


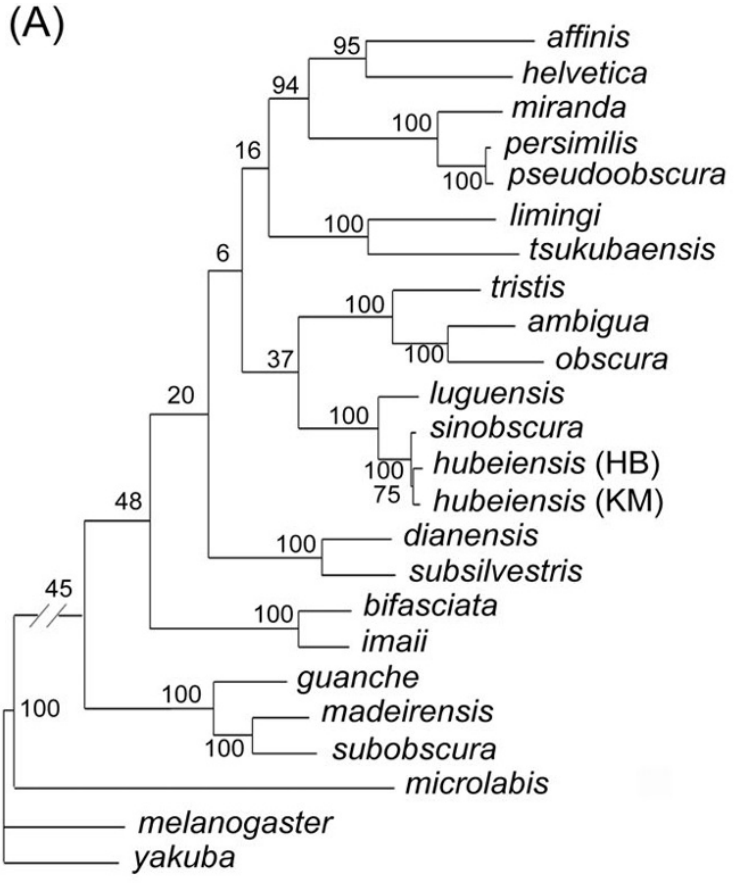

10 substitutions

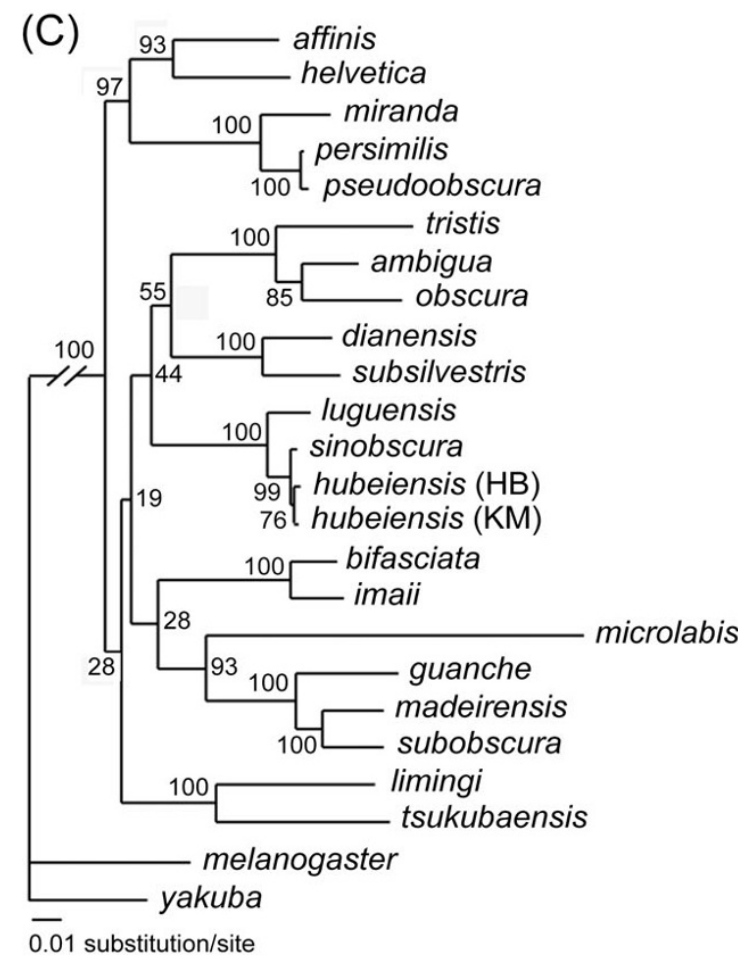

(B)

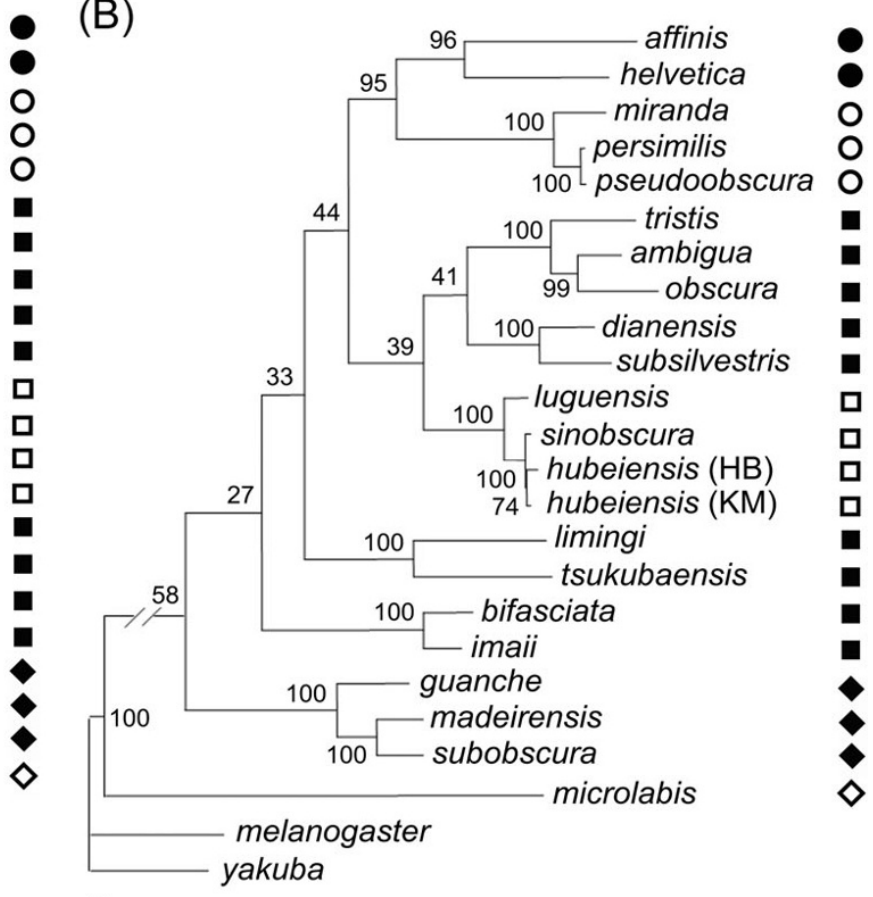

$\overline{10}$ substitutions
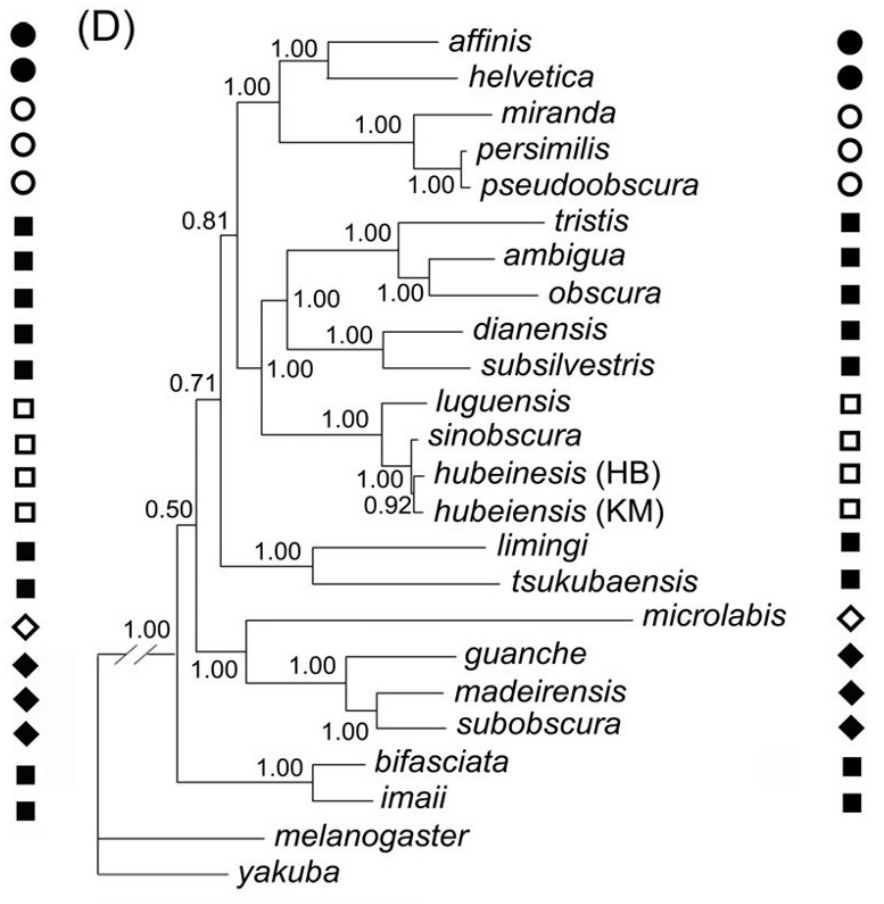

0.1 substitution/site

\section{Figure 2}

Phylogenetic trees based on NT data. (A) A single MP tree constructed with un-weighted scheme (tree length $=3233 ; \mathrm{Cl}$ $=0.4930 ; \mathrm{RI}=0.558 \mathrm{I}$ ); (B) A single MP tree constructed with six-parameter weighting scheme (tree length $=23 \mathrm{I} 3.3 \mathrm{I} 0 \mathrm{I}, \mathrm{Cl}=$ $0.5016, \mathrm{RI}=0.6059)$; (C) ML tree (-In $L=20990.05)$; (C) Bayesian tree. Numbers besides nodes indicate bootstrap values in (A), (B) and (C), but posterior probabilities in (D). Symbols indicate the taxonomic assignment of species: affinis subgroup (O); pseudoobscura subgroup $(\bigcirc)$; obscura subgroup $(\square)$; sinobscura subgroup $(\square)$; subobscura subgroup $(\diamond)$; microlabis subgroup $(\diamond)$. 
(A)

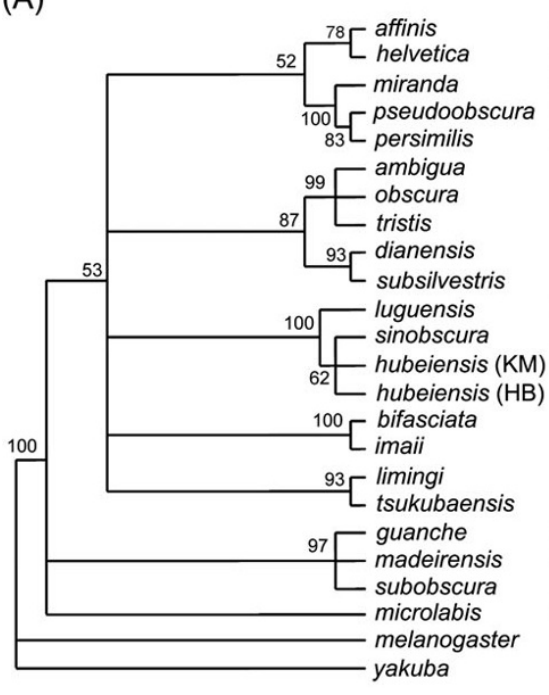

(B)

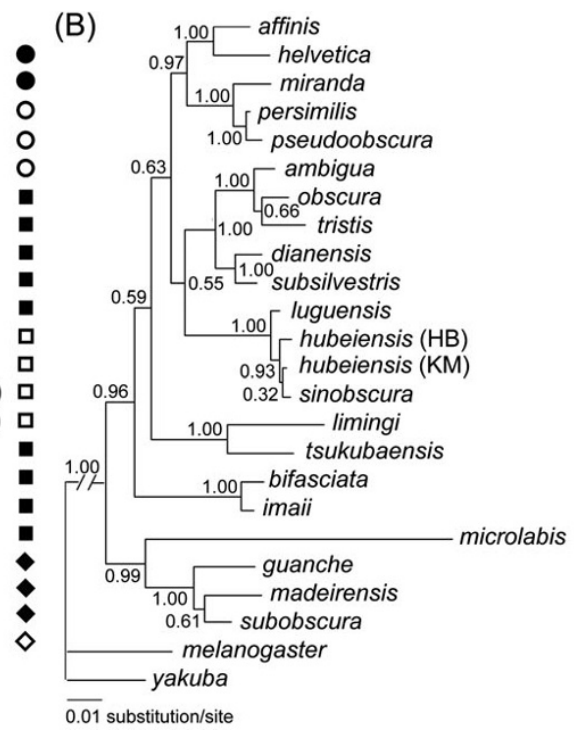

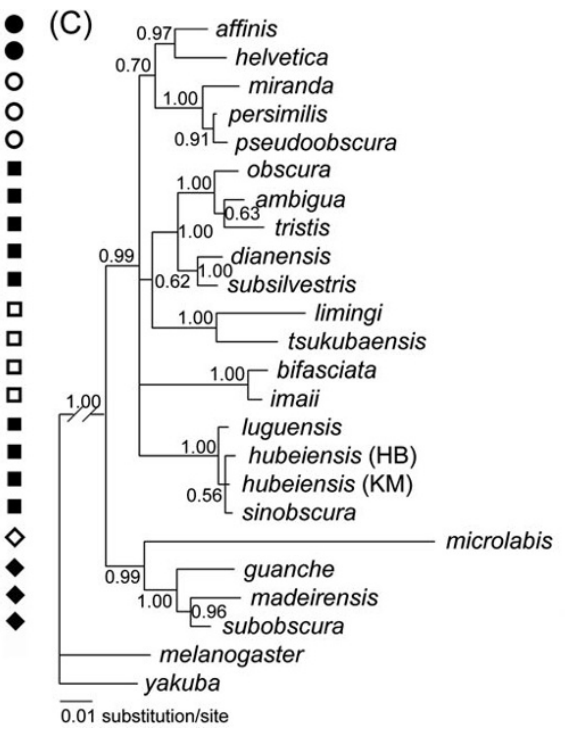

Figure 3

Phylogenetic trees based on AA data set. (A) Strict consensus of 17 equally parsimonious trees (tree length $=433, \mathrm{Cl}=$ $0.7367, \mathrm{RI}=0.7355$ ); (B) Bayesian tree inferred with the Poisson model, with gamma-distributed rate variation across sites and a proportion of invariable sites; (C) Bayesian tree inferred with the GTR model, with gamma-distributed rate variation across sites and a proportion of invariable sites. Numbers besides nodes are bootstrap values of 1000 replicates in (A); those in (B) and $(C)$ are posterior probabilities. Symbols are same as in Figure 2.

The Bayesian trees with AA data (Figures 3B, 3C) support with high confidences a basal position of the microlabissubobscura clade in the obscura group. This relationship is also suggested by previous cladistic analyses [13]. In some previous studies lacking any representative of the microlabis subgroup $[10,12,38]$, the subobscura subgroup alone was placed as basal to the rest in the obscura group. Moreover, comparison of more than 48 morphological characters among obscura group species (except for the microlabis and sinobscura subgroups) suggests that $D$. subobscura (as the only representative of the subobscura subgroup) differs more from the other Eurasian species than the latter differ from each other [39].

The monophyly of the obscura cluster is also suggested by morphological data: in the obscura group, $D$. dianensis, $D$. subsilvestris and D. obscura are the only species characterized by pale spots on several abdominal tergites in female $[30,40]$, and large, somewhat quadrate 10th sternite in male $[30,41]$. In the present study, the obscura cluster appears to be most closely related to the sinobscura subgroup, while the remainder species of the obscura subgroup, i.e., the $D$. limingi/D. tsukubaensis pair and $D$. bifasciata/D. imaii pair, appear to have diverged earlier. Based on these evidences, we propose here a revised notion of the obscura subgroup, i.e., the cluster of the five species D. ambigua, D. obscura, D. tristis, D. dianensis and D. subsilvestris.
Consistent with some previous study [27], the present study clusters the Palearctic $D$. helvetica with the Nearctic $D$. affinis with strong support, clearly indicating its adscription to the affinis subgroup. Morphologically, $D$. helvetica possesses some diagnostic characters pertained to the affinis subgroup, e.g., very small distal sex-comb, 6 rows of acrostichal setulae. Some morphological similarities between $D$. helvetica and $D$. tolteca, a member of the affinis subgroup, are also found [40]. Given the Old World Origin of the obscura group [42] and the monophyletic nature of the affinis-pseudoobscura clade, D. helvetica undoubtedly represents a refluence of the New World element back into the Old World.

It was demonstrated that Bayesian posterior probability can overestimate the true probability of node confidences if substitution model used for phylogenetic analysis is oversimplified [43], and/or if concatenated sequences data are used [44]. In the 6pMP and ML trees of NT data, the BP supports for the obscura cluster are relatively low, and so are the BP supports for the obscura-sinobscura cluster. However, the corresponding PP values in the Bayesian tree of NT data seem to be excessively high. Also in the analyses with AA data, a remarkable discrepancy between $\mathrm{BP}$ and PP is found for the large clade consisting of the affinis, pseudoobscura, sinobscura, and obscura subgroups. In our Bayesian analysis with NT data, partition-specific models are used. The Bayesian analyses of AA data with 


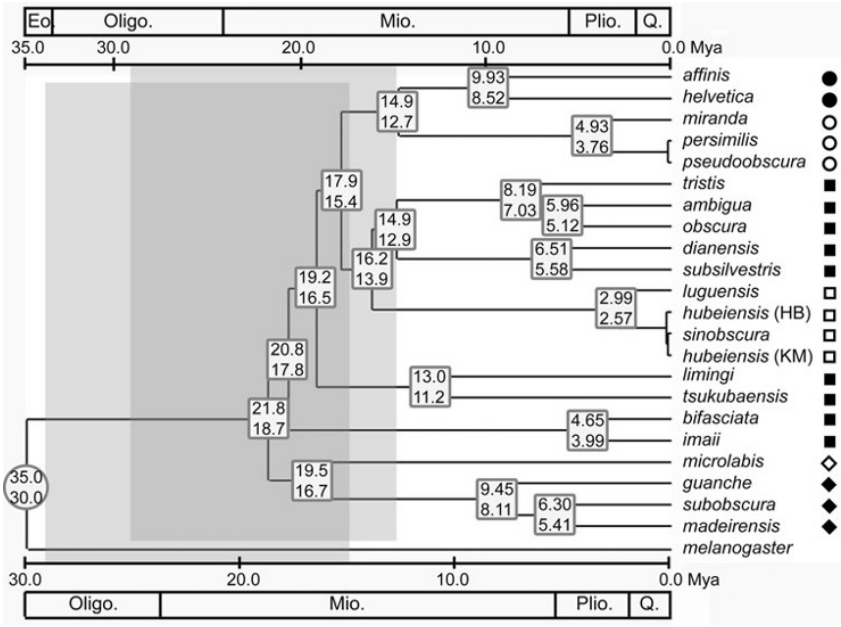

Figure 4

Linearized ML tree deduced from concatenated nucleotide sequences of the $\mathbf{4}$ mitochondrial loci. A time interval of 30-35 Mya for the obscura-melanogaster divergence [9] was used as calibration. Shaded areas (gray) indicate the time span of temperate forest developing in the Northern Hemisphere [50]. The numbers in the circle indicate the calibration points, and those in the panes indicate the estimated intervals of divergence times in light of the calibration points. For some very recent divergences, the estimates are not shown. Abbreviations: Eo. = Eocene; Oligo. = Oligocene; Mio = Miocene; Plio. = Pliocene; Q. = Quaternary. Symbols are same as in Figure 2.

simple (Poisson) and comprehensive (GTR) models yield comparable PP supports for the above relationships. Therefore, the great discrepancy between BP and PP may be partially due to our using of concatenated sequences. On the other hand, it was shown that BP in ML analyses is generally a conservative estimate of statistical confidence [44], and that compared to the BP in ML analyses, BP in MP analyses shows lower correlation with Bayesian PP [45].

The effect of taxon sampling on phylogenetic accuracy has been addressed by a number of studies [46-49], most of which favor addition of taxa, especially for breaking up long branches to improve information about state of internal nodes and rate at individual sites [47]. In the present study, adding of a number of Old World taxa enables us to trace some additional, ancient branching events, resulted in some largely congruent basal relationship in the obscura group, e.g., the close relationship between the $D$. ambigua triad and the $D$. dianensis/D. subsilvestris pair, that between the obscura cluster and the sinobscura subgroup, and the sister relationship between the microlabis and subobscura subgroups. The obscura group is presently known for 41 described and at least 2 undescribed species.

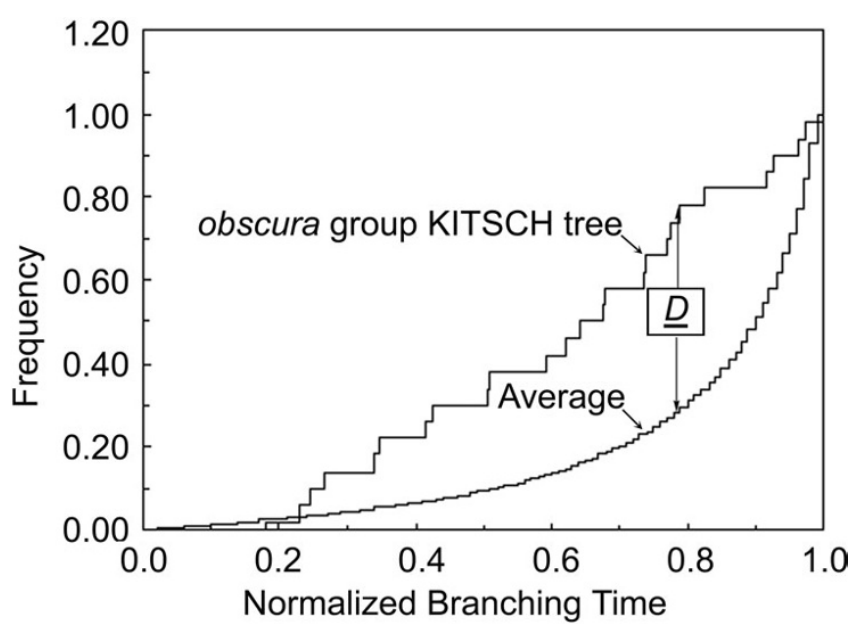

Figure 5

CFD of normalized branching times for the KITSCH trees of $\mathbf{2 7}$ obscura group species. The largest difference between empirical and expected CFDs is indicated.

Future studies with denser taxon sampling and larger number of characters (especially for nuclear gene sequence characters) are desirable to fully resolve the basal relationship in this group.

\section{Temporal pattern of evolution}

Throckmorton's [42] study with data of palegeography and fossil record has proposed that the founder of the obscura group arose and existed for short time before its expanding with the temperate forest. The temperate forest was proposed to began to spread in Northern Hemisphere with decreasing of temperature by about $10 \sim 15^{\circ} \mathrm{C}$ in Oligocene [50]. However, according to our time estimation (Figure 4), the Old World diversification of the obscura group began well after the origin of this group. By the mid-Miocene time, at least half of the current major lineages had come into being, indicating a more or less rapid major radiation of the obscura group. This is also suggested by the results of statistical test of temporal pattern (Figure $5)$, and reflected by the short internal branches in the phylogenetic trees (e.g., Figures 2C, 2D, 3B and 3C). On the other hand, obvious nucleotide substitution saturation (Figure 1) and base composition bias have been observed in the mitochondrial loci. All these results lend supports to the previous proposal [12] that either the rapid radiation, or the special evolutionary dynamics of the mtDNA in the obscura group may account for the phylogenetic predicament concerning the obscura group.

\section{Biogeography and history of adaptive radiation}

Two major patterns during the evolution of the family Drosophilidae have been proposed by Throckmorton [42] based on morphological and biogeographical data: 
1) the primary tropical disjunction involving species groups, subgenera and genera; and 2) the temperate-forest disjunction involving species subgroups and species, represented typically by the obscura species group. Due to lacking of data about drosophilid faunas from either the Afrotropical or the Oriental region, the disjunction pattern of the obscura group within the Old World was thought to be not clear [42]. However, the pattern is now much more clearly seen: there are about 14 species ( 3 of the subobscura subgroup, 4 of the microlabis subgroup, 1 of the affinis subgroup, 5 of the obscura subgroup, and 1 ungrouped) are restricted to or mainly distributed in Europe/the Afrotropical region; and at least 11 species (3 of the sinobscura subgroup, 6 of the obscura subgroup, and 2 undescribed) restricted to East/Southeast Asia. Among the Eurasian species of the obscura group, at least 9 are restricted or mainly distributed in the Oriental region, with the southmost records from the Mt. Kinabalu of Malaysia. This clearly indicates a thorough adaptation of the group into high-elevation temperate-like habitats in the Oriental region, a pattern parallel to those in the Afrotropical and Neotropical regions $[8,51,52]$.

Our time estimation for the major radiation of the obscura group is overlapped largely to the hypothetical time span of the developing of temperate forest in Northern Hemisphere (mid-Oligocene to mid-Miocene) [50,53]. It was proposed based on biogeographical data that, from the mid-Tertiary times, the temperate drosophilid faunas developed and spread with the temperate forest, until the time of the temperate-forest disjunction in mid Miocene age [42]. It is very likely that the fragmentation of the temperate forest had enforced the Old World diversification, and that the gradual desertification of the Asia interior onset from the early Miocene epoch [54] played important role in enforcing the disjunction of the temperate forest and thus the east-west disjunction of the obscura group within the Old World.

The cooling of the climate in the Qinghai-Tibet area of South Asia resulted from the uplift of the Qinghai-Tibet Plateau in the Tertiary period was thought to provide favorable conditions for the Palearctic insect fauna to invade southwards [55]. It is reasonable to presume that changing of climate might have also facilitated the adaptation of the founders of the Oriental elements of the obscura group into South Asia. Probably the intensified uplift of the plateau in late Pliocene [55] has accelerated these elements (e.g., the sinobscura subgroup, initiated to diversify 2.63.0 Mya) to spread around, giving rise to the current species in south China, India and Malaysia.

\section{Conclusion}

In conclusion, our phylogenetic study suggests that, the obscura group began to diversify rapidly in the Old World before invaded into the New World. Among the Old World lineages, the microlabis and subobscura subgroups form a monophyletic group basal to the rest of the obscura group. Our results corroborate the finding by the previous studies that the traditional obscura group is paraphyletic, with some of its members (the D. ambigua triad plus the $D$. dianensis/D. subsilvestris pair) forming a monophyletic cluster, which appears to be most closely related to the sinobscura subgroup.

\section{Methods}

Samples, DNA extraction, PCR, cloning and sequencing

Samples of twenty-one species of the D. obscura group and one species of the D. melanogaster group (Table 2) were used for DNA sequencing. DNA was extracted from single fly by standard phenol-chloroform method. The PCR cycle program comprised an initial 2 min of predenaturation at $94^{\circ} \mathrm{C}, 35$ cycles of amplification (50 s of denaturation at $94^{\circ} \mathrm{C}$; 1 min of annealing at $55^{\circ} \mathrm{C}$ for ND2 and COII, $51.5^{\circ} \mathrm{C}$ for $C y t b, 52^{\circ} \mathrm{C}$ for COI and $A d h, 60^{\circ} \mathrm{C}$ for $28 S ; 1 \mathrm{~min}$ of extension at $72^{\circ} \mathrm{C}$ ), and $5 \mathrm{~min}$ of sequence postextension at $72^{\circ} \mathrm{C}$. The primers (all given left to right from $5^{\prime}$ to $3^{\prime}$ ends) for the PCR and sequencing of the ND2, COI, COII, Cyt $b$ and $28 S$ genes were: nd2-1 ATATT TACAG CTTTG AAGG, and nd2-2 AAGCT ACTGG GTTCA TACC for the ND2 gene [56]; UEA5 AGTTC TAGCA GGAGC TATTA CTAT, and UEA8 AAAAA TGTTG AGGGA AAAAT GTTA for the COI gene [57]; coii-1 ATGGC AGATT AGTGC AATGG and coii-2 GTTTA AGAGA CCAGT ACTTG [13] for the COII gene; $C y t b$-F TTATG GTTGA TTATT ACGAA, and $C y t b$-R CAAAA CATAT GCTTA TTCAA for the $C y t b$ gene; 28S-H CCCGA AGTAT CCTGA ATCTT TCGCA TTG (designed by T. Katoh in Hokkaido University), and 28S-T TCTTA GTAGC GGCGA GCG [58] for the $28 S$ gene. PCR products were separated on $2.0 \%$ agarose gels, then excised from the gels and purified using Watson $^{\mathrm{TM}}$ gel extraction mini kit (Watson Biotechnologies).

The Adh fragments of $D$. hubeiensis (KM), D. luguensis, D. dianensis, and $D$. limingi were amplified using the primers adh-e2+ CTGGAC TTCTG GGACA AGCG, and adh-e3TAGAT GCCCG AGTCC CAGTG [27], and the PCR product was cloned into the PMD18-T Vector (TaKaRa), then transformed into Escherichia coli as host. Thereafter, the recombinant DNA was extracted then, and the Adh fragment was sequenced with the M13 universal primers AAGCT TGCAT GCCTG CAGGT CGACG and CGGTA CCCGG GGATC CTCTA GAGAT. After purifying of the product of sequence reaction, the sequences were determined using ABI 377 or $\mathrm{ABI} 3700$ sequencer according to the protocol by manufacturer. 


\section{Sequence aligning and characterization}

The newly collected sequences were edited using the Editseq module of the DNAStar package [59]. For each of the ND2, COI, COII, Cyt b, Adh and $28 S$ gene fragment, homologous GenBank sequences were downloaded and aligned with newly determined sequences by the ClustalW method [60]. The intron region of the Adh gene was excluded from all analyses. The alignment was then adjusted by eye to make it conform to the codon assignments. Then the ends of a few COI and $28 S$ sequences were trimmed slightly, so as to make the majority of homologous sequences well overlapped. We use MEGA3 [61] to calculate base composition and ti/tv ratios in each data partitions. Detection of substitution saturation in mitochondrial and nuclear data partitions was performed by plotting the ratio ti/tv for sequence pairs versus corresponding number of whole substitutions with respect to codon positions ( $1 \mathrm{st}+2 \mathrm{nd}$ or $3 \mathrm{rd}$ ), with the pairwise ratios and numbers of substitutions calculated in MEGA3 [61], and plots worked out with the Microsoft Excel program. Only ingroup species are included for saturation analysis.

\section{Pairwise partition homogeneity test (PHT) and phylogenetic analyses}

Before the phylogenetic analyses, the NT data was subjected to pairwise PHT [62] between data partitions of different loci under either un-weighted or six-parameter weighting parsimony scheme $[63,64]$ with PAUP* $4.0 \mathrm{~b} 10$ [65], with heuristic search for 1000 replicates. Modeltest 3.6 [66] was used to estimate parameters of DNA substitution model for the six-parameter MP, ML and BI analyses.

Phylogenetic analyses with NT data set were performed using MP, ML and Bayesian inferring methods. The MP tree was constructed with either un-weighted or sixparameter weighting parsimony methods with heuristic search (initial trees obtained by 100 replicates random addition; branch swapping with TBR algorithm). For the six-parameter method, models specific to each locus were implemented in PAUP*4.0b10 [65], with each substitution classes was weighted based on its substitution rate $\left(\mathrm{R}_{\mathrm{ij}}\right.$, i.e., rate of transformation between nucleotide $\mathrm{i}$ and j) estimated with Modeltest3.6 [66]: $\mathrm{w}_{\mathrm{ij}}=-\ln \left(\mathrm{R}_{\mathrm{ij}} / \sum \mathrm{R}_{\mathrm{i}}\right)$. The weighting parameter stepmatrix for each locus was adjusted for satisfaction of triangle inequality in PAUP*4.0b10 [65]. To access the support level for each node on the MP trees, bootstrap (BP) [67] analyses were performed with 1000 replicates and heuristic search. The MP analysis with AA data was performed with similar strategy as that of the NT data set.

The ML analysis of NT data was performed using PAUP*4.0b10 [65], with parameters assigned as follows: base frequencies of A (respectively $\mathrm{C}, \mathrm{G}$ and $\mathrm{T}$ ) $=0.3089$ (respectively $0.1385,0.1319$ and 0.4207 ); substitution rates of A-C (respectively A-G, A-T, C-G, C-T and G-T) = 2.0353 (respectively 13.2831, 6.7964, 5.9419, 33.5370 and 1.0000); proportion of invariable sites $(I)=0.5765$; and gamma distribution shape parameter $(\alpha)=0.8598$.

Bayesian inferring was implemented in MrBayes3.1 [68]. The starting tree was randomly selected and four chains were run. For the analysis with NT data set, parameters are set as follows: "nst = 6" + "invgamma" applied to the character partition of mitochondrial genes, "nst $=6 "+$ "gamma" to that of the Adh gene, and "nst $=2 "+$ "gamma" to that of the $28 S$ gene. Bayesian analyses of AA data were performed with either the Poisson or the GTR models, with gamma-distributed rate variation across sites and a proportion of invariable sites. For all the Bayesian analyses, two independent runs were implemented in parallel, with the Markov chains been sampled every 100 cycles. The runs were stopped after 2,000,000 cycles of MCMC (Markov Chain Monte Carlo) for NT data, but $1,000,000$ cycles for AA data, till the average deviation of split frequencies fall well below 0.01. For all the runs, 1,000 trees sampled at early phase of the chain (well before the end of this phase, the likelihood values stop to increase, and start to fluctuate within a stable range) were discarded, and the remainders were summarized to obtain a majority rule tree which showing all the compatible partitions.

Estimates of divergence times in the obscura species group Before estimating divergence times, relative-rate test using the program Phyltest2.0 [69] is conducted to examine constancy of sequence evolution between lineages in the obscura group. Since no time calibration point of fossil record or by geological dating is available for our estimation, we cite that used by Beckenbach et al. [9]: an interval of 30-35 Mya for the divergence between the obscura and melanogaster groups. The program r8s1.71 [70], which enables estimating divergence time in the absence of a molecular clock, is used to estimate the divergence times in the obscura species group. A ML tree constructed with mtDNA sequence data was used as the input tree file for time estimating. The model for the ML search is selected by Modeltest3.6 [66]: base frequencies are 0.3246, $0.1028,0.1116$ and 0.4610 for A, C, G and T, respectively; rates $=3.4175,25.8349,10.1514,4.7640,86.1667$ and 1.0000 for A-C, A-G, A-T, C-G, C-T and G-T, respectively; $I=0.5629 ; \alpha=1.0481$. A penalized likelihood (PL) [71] method is used for divergence time reconstructing, with a truncated Newton (TN) algorithm for finding optima of the objective functions. Cross-validation are checked over a range of smoothing values by set the parameters cvstart $=0$, cvinc $=0.5$ and cvnum $=10$. Divergence time for all the nodes except for the root is estimated by rerunning of the input data with a selected smoothing parameter (= 
316, which has the lowest cross-validation score) by checking of the cross-validation.

\section{Statistic test of the temporal pattern of evolutionary diversity}

We perform a statistic test [33] of temporal pattern in the obscura group. To reduce the effect of incomplete sampling of extant taxa, GenBank sequences of some additional obscura group species (Table 3 ) are also used. Based on the aligned sequence of 27 obscura group species, a F84 distance data matrix is created, and a so-called KITSCH tree is constructed, using the program DNADIST and KITSCH, respectively, both packed in Phylip3.6 [72]. For distance estimating using DNADIST, shape parameters of the Gamma distribution ( $\alpha=1.0353)$ and base frequencies $(\mathrm{A}=0.3132 ; \mathrm{C}=0.1401 ; \mathrm{G}=0.1320 ; \mathrm{T}=0.4147)$ are estimated in Modeltest3.6 [66], and the ratio of ti/tv (= 1.1) is calculated in MEGA3 [61]. The branching times for the resulted KITSCH tree were normalized between zero (the time of the first branching event) and one (the present), cumulative frequency distribution (CFD) [34] of the scaled branching times for all the nodes $(n=25)$ in the tree is plotted. The dissimilarity between the resulted empirical CFD and expected (i.e., average) CFD specific for same number of extant taxa was quantified using a Kolmogorov-Smirnov (K-S) goodness-of-fit statistic $D$ [34]. The average CFD for specific number of extant species has been generated by Wallenberg et al. [33] by computer simulations under null model of stochastic lineage bifurcation and extinction. Therefore, we get the average CFD for 27 extant taxa by interpolated those for 25 and 30 taxa [33].

\section{Authors' contributions}

JG participated in design of the study, acquired the data, analyzed the data, and drafted the manuscript; HW and TA participated in conception and design of the study, critically revised intellectual content of the manuscript; JP participated in analysis and interpretation of data; YZ conceived the study and participated in its design and data interpretation, and preparing the manuscript. All authors read and approved the final manuscript.

\section{Acknowledgements}

We thank Drs. W. Pinsker, E. Haring, L. Serra, and H. Takamori for providing us with samples. We are grateful to Drs. M.J. Toda, G. Baechli, E. Haring, and two anonymous reviewers for their invaluable suggestions and comments. The present study was supported by grants of the State Key Basic Research and Development Plan, NSFC (30460026, 3062 1092), Bureau of Science and Technology of Yunnan Province, and JSPS (No. 12375002, 16370040, 19570077).

\section{References}

I. Dobzhansky T, Powell JR: Drosophila pseudoobscura and its American relatives, D. persimilis and D. miranda. In Hand Book of Genetics Volume 3. Edited by: King RC. New York: Plenum; 1975:537-587.

2. Powell JR: Progress and Prospects in Evolutionary Biology: The Drosophila Model New York: Oxford Univ Press; 1997.
3. Richards S, Liu Y, Bettencourt BR, Hradecky P, Letovsky S, Nielsen R, Thornton K, Hubisz MJ, Chen R, Meisel RP, Couronne O, Hua S, Smith MA, Zhang P, Liu J, Bussemaker HJ, van Batenburg MF, Howells SL, Scherer SE, Sodergren E, Matthews BB, Crosby MA, Schroeder AJ, Ortiz-Barrientos D, Rives CM, Metzker ML, Muzny DM, Scott G, Steffen D, Wheeler DA, Worley KC, Havlak P, Durbin KJ, Egan A, Gill R, Hume J, Morgan MB, Miner G, Hamilton C, Huang Y, Waldron L, Verduzco D, Clerc-Blankenburg KP, Dubchak I, Noor MA, Anderson W, White KP, Clark AG, Schaeffer SW, Gelbart W, Weinstock GM, Gibbs RA: Comparative genome sequencing of Drosophila pseudoobscura: chromosomal, gene, and cis-element evolution. Genome Res 2005: I-18.

4. Goddard K, Caccone A, Powell JR: Evolutionary implication of DNA divergence in the Drosophila obscura group. Evolution 1990, 44: 1656-1670.

5. Powell JR, DeSalle R: Drosophila molecular phylogenies and their uses. Evol Biol 1995, 28:87-138.

6. Carvalho AB, Clark AG: Y chromosome of $D$. pseudoobscura is not homologous to the ancestral Drosophila Y. Science 2005, 307:108-110.

7. Prud'homme B, Rokas A, Kassner VA, Willianms TM, Yeh S, True JR, Carroll SB: Repeated morphological evolution through cis-regulatory changes in a pleiotropic gene. Nature 2006, 440:1050-1053.

8. Lakovaara S, Saura A: Evolution and speciation in the Drosophila obscura group. In The Genetics and Biology of Drosophila Volume $3 b$. Edited by: Ashburner M, Carson HL, Thompson JN. London: Academic Press; 1982:2-59.

9. Beckenbach AT, Wei YW, Liu H: Relationship in the Drosophila obscura group, inferred from mitochondrial cytochrome oxides-II sequences. Mol Biol Evol 1993, 10:619-634.

10. Barrio E, Latorre A, Moya A: Phylogenetic of the Drosophila obscura species group deduced from mitochondrial DNA sequences. J Mol Evol I994, 39:478-488.

II. Gleason JM, Caccone A, Moriyama EN, White KP, Powell JR: Mitochondrial DNA phylogenies for the Drosophila obscura group. Evolution 1997, 5 1:433-440.

12. Barrio E, Ayala FJ: Evolution of the Drosophila obscura species group inferred from Gpdh and Sod genes. Mol Phylogenet Evol 1997, 7:79-93.

13. O'Grady PM: Reevaluation of phylogeny in the Drosophila obscura species group based on combined analysis of nucleotide sequence. Mol Phylogenet Evol 1999, 12:124-139.

14. Ruttkay H, Solignac M, Sperlich D: Nuclear and mitochondrial ribosomal RNA variability in the obscura group of Drosophila. Genetics 1992, 85: |31-138.

15. Watabe H, Bachmann L, Haring E, Sperlich D: Taxonomic and molecular study on Drosophila sinobscura and hubeiensis, two sibling species of the D. obscura group. J Zool Syst Evol Res 1997, 35:81-94.

16. Lewis DL, Farr CL, Kaguni LS: Drosophila melanogaster mitochondrial DNA: completion of the nucleotide sequence and evolutionary comparisons. Insect Mol Biol 1995, 4:263-278.

17. Clary DO, Goddard JM, Martin SC, Fauron CM, Wolstenholme DR: Drosophila mitochondrial DNA: a novel gene order. Nucleic Acids Res 1982, 10:6619-6637.

18. Clary DO, Wolstenholme DR: The mitochondrial DNA molecular of Drosophila yakuba: nucleotide sequence, gene organization, and genetic code. J Mol Evol 1985, 22:252-271.

19. de Brujin MH: Drosophila melanogaster mitochondrial DNA, a novel organization and genetic code. Nature 1983, 304:234-24I.

20. Mafany G, Gonzalez-Duarte R: The Adh genomic region of Drosophila ambigua: evolutionary trends in different species. J Mol Evol 1991, 32:454-462.

21. Hagemann S, Haring E, Pinsker W: Repeated horizontal transfer of $P$ transposons between Scaptomyza pallida and Drosophila bifasciata. Genetica 1996, 98:43-5I.

22. Mafany G, Gonzalez-Duarte R: The Drosophila subobscura Adh genomic region contains valuable evolutionary markers. Mol Biol Evol 1992, 9:26I-277.

23. Mafany G, Gonzalez-Duarte R: Characterization and evolution of the Adh genomic region in Drosophila guanche and Drosophila madeirensis. Mol Phylogenet Evol 1993, 2:13-22.

24. Schaeffer SW, Miller EL: Molecular population genetics of an electrophoretically monomorphic protein in the alcohol dehydrogenase region of Drosophila pseudoobscura. Genetics 1992, 132:163-178.

25. Schaeffer SW, Miller EL: Nucleotide sequence analysis of Adh genes estimates the time of geographic isolation of the Bogota population of Drosophila pseudoobscura. Proc Natl Acad Sci USA |99|, 88:6097-6I0I. 
26. Kreitman M: Nucleotide polymorphism at the alcohol dehydrogenase locus of Drosophila melanogaster. Nature 1983, 304:412-417.

27. Haring E, Hagemann S, Lankimen P, Pinsker W: The phylogenetic position of Drosophila eskoi deduced from $P$ element and Adh sequence data. Heredity 1998, I 28:235-244.

28. Pelendakiz M, Solignac M: Molecular phylogeny of Drosophila based on ribosomal RNA sequences. J Mol Evol 1993, 37:525-543.

29. Cunningham CW: Can three incongruence tests predict when data should be combined? Mol Boil Evol 1997, I 4:733-740.

30. Gao JJ, Watabe H, Toda MJ, Zhang YP, Aotsuka T: The Drosophila obscura species-group (Diptera, Drosophilidae) from Yunnan Province, Southern China. Zool Sci 2003, 20:773-782.

31. Tamura K, Subranmanian S, Kumar S: Temporal Patterns of Fruit Fly (Drosophila) Evolution Revealed by Mutation Clocks. Mol Biol Evol 2004, 2 I:36-44.

32. Russo CAM, Takezaki N, Nei M: Molecular phylogeny and divergence times of drosophilid species. Mol Biol Evol 1995, 1 2:39|-404.

33. Wallenberg K, Arnold J, Avise JC: Recognizing the forest for the trees: testing temporal patterns of cladogenesis using a null model of stochastic diversification. Mol Biol Evol 1996 13:833-849.

34. Sokal RR, Rohlf FJ: Biometry: the principles and practice of statistics in biological research New York: Freeman; 1995.

35. Aderson FE, Swofford DL: Should we be worried about longbranch attraction in real data sets? Investigations using metazoan I8S rDNA. Mol Phylogenet Evol 2004, 33:440-45I.

36. Swofford DL, Waddell PJ, Huesenbeck JP, Foster PG, Lewis PO, Rogers IS: Bias in phylogenetic estimation and its relevance to the choice between parsimony and likelihood methods. Syst Biol 200I, 50:525-239.

37. Mar JC, Harlow TJ, Ragan MA: Bayesian and maximum likelihood phylogenetic analyses of protein sequence data under relative branch-length differences and model violation. BMC Evol Biol 2005, 5:8.

38. Goto SG, Yoshida T: Evolution of overwintering strategies in Eurasian species of the Drosophila obscura species group. Biol ] Linnaean Soc 1999, 68:429-441.

39. Buzzati-Traverso AA, Scossiroli RE: The obscura group of the genus Drosophila. Adv Genet 1955, 7:47-92

40. Baechli G, Vilela CR, Escher SA, Saura A: The Drosophilidae (Diptera) of Fennoscandia and Denmark New York: Brill; 2004: I 24- I27. [Kristensen NP (Editor in Chief): Fauna Entomoleogica Scandinavica, Vol 39.]

41. Okada: Systematic study of Drosophilidae and allied families of Japan Tokyo: Gihodo; 1956.

42. Throckmorton LH: The phylogeny, ecology, and geography of Drosophila. In Handbook of genetics Volume 3. Edited by: King RC. New York: Plenum Press; 1975:42 1-469.

43. Bayesian Phylogenetic Inference and MCMC [http:// www.csit.fsu.edu/ ronquist/mrbayes/Bayesianlnference I.ppt]

44. Suzuki Y, Glazko GV, Nei M: Overcredibility of molecular phylogenies obtained by Bayesian phylogenetics. Proc Natl Acad Sci USA 2002, 99:16138-16|43.

45. Alfaro ME, Zoller S, Lutzoni F: Bayes or bootstrap? A simulation study comparing the performance of Bayesian Markov Chain Monte Carlo sampling and bootstrapping in assessing phylogenetic confidence. Mol Biol Evol 2003, 20:255-266.

46. Graybeal A: Is it better to add taxa or characters to a difficult phylogenetic problem? Syst Biol 1998, 47:9-17.

47. Pollock DD, Bruno WJ: Assessing an unknown evolutionary process: Effect of increasing site-specific knowledge through taxon addition. Mol Biol Evol 2000, I 7:1854-1858.

48. Pollock DD, Zwickl DJ, McGuire JA, Hillis DM: Increased taxon sampling is advantageous for phylogenetic inference. Syst Biol 2002 51:664-67I.

49. Hillis DM, Pollock DD, McGuire JA, Zwickl DJ: Is sparse taxon sampling a problem for phylogenetic inference? Syst Biol 2003 52:124-126.

50. Zubakov VA, Borzenkova II: Global Paleoclimate of the late Cenozoic. In Developments in paleontology and stratigraphy New York: Elsevier; 1990:224-227.

51. Cariou ML, Lachaise D, Tsacas L, Sourdis J, Krimbas C, Ashburner M: New African species in the Drosophila obscura species group: genetic variation, differentiation and evolution. Heredity 1988 61:73-84.

52. Heed WB, O'Grady PM: Drosophila maya, a new Neotropical member of the Drosophila obscura species group (Diptera: Drosophilidae). J New York Entomol Soc 2000, I 08:98-105.

53. Origin of Temperate Forests in the Northern Hemisphere $X$ WORLD FORESTRY CONGRESS, VOLUME 6, TOPIC 38.2: 13-22 October 1997; Antalya, Turkey [http://www.fao.org/forestry/docrep/wfcxi/ PUBLI/V6/T382E/3-3.HTM].
54. Guo ZT, Ruddiman WF, Hao QZ, Wu HB, Qiao YS, Zhu RX, Peng SZ, Wei J], Yuan BY, Liu TS: Onset of Asian desertification by 22 Myr ago inferred from loess deposits in China. Nature 2002, 416:159-163.

55. Wang $\mathrm{BH}$, Yuan WH, Wang CM, Huang FS, Tang ZH, Lin DW: The Tibetan Insect Fauna and Its Evolution Zhengzhou: Henan Science and Technology Publishing House; 1992:133-151.

56. Park J: Molecular phylogenetic studies of the Drosophila (Drosophila) virilis section (Diptera, Drosophilidae). In Ph D Thesis Tokyo Metropolitan University; 1999.

57. Zhang DX, Hewitt GM: Assessment of the universality and utility of a set of conserved mitochondrial $\mathrm{COI}$ primers in insects. Ins Mol Biol 1996, 6:143-150.

58. Kopp A, True JR: Phylogeny of the Oriental Drosophila melanogaster species group: a multilocus reconstruction. Syst Bio 2002, $51: 786-805$

59. DNAStar [http://www.dnastar.com/

60. Thompson JD, Higgins DG, Gibson T]: Clustal W: improving the sensitivity of progressive multiple sequence alignment through sequence weighting, position specific gap penalties and weight matrix choice. Nucleic Acids Res 1994, 22:4673-4680.

61. Kumar S, Tamura K, Nei M: MEGA3: Integrated software for Molecular Evolutionary Genetics Analysis and sequence alignment. Briefings in Bioinformatics 2004, 5: 150-163.

62. Farris JS, Kallersio $M$, Kluge AG, Bult $C$ : Testing significance of incongruence. Cladistics 1994, 10:315-319.

63. Cunningham: Is congruence between data partitions a reliable predictor of phylogenetic accuracy? Empirically testing an iterative procedure for choosing among phylogenetic methods. Syst Biol 1997, 46:464-478.

64. Stanger-Hall K, Cunningham CW: Support for a monophyletic Lemuriformes: overcoming incongruence between data partitions. Mol Biol Evol 1998, 15:1572-1577.

65. Swofford DL: PAUP*: Phylogenetic Analysis Using Parsimony (*and Other Methods). Version 4. Sinauer Associates, Sunderland, Massachusetts; 2003.

66. Posada D, Crandall KA: Modeltest: test the model of DNA substitution. Bioinformatics 1998, 14:817-818.

67. Felsenstein J: Confidence limits on phylogenies: an approach using the bootstrap. Evolution 1985, 39:783-79|

68. Ronquist F, Huelsenbeck JP: MrBayes 3: Bayesian phylogenetic inference under mixed models. Bioinformatics 2003, 19:1572-1574.

69. Kumar S: Phyltest: a program for testing phylogenetic hypothesis, Version 2.0. Institute of molecular evolutionary genetics and department of biology, the Pennsylvania state university, University Park, Pennsylvania, USA; 1996.

70. Sanderson MJ: r8s: inferring absolute rates of molecular evolution and divergence times in the absence of a molecular clock. Bioinformatics Applications Note 2003, 19:301-302.

7I. Sanderson MJ: Estimating absolute rates of molecular evolution and divergence times: A penalized likelihood approach. Mol Biol Evol 2002, 19:101-109.

72. Felsenstein J: PHYLIP (Phylogeny Inference Package) version 3.6. In Distributed by the author Department of Genome Sciences, University of Washington, Seattle; 2004.

Publish with Bio Med Central and every scientist can read your work free of charge

"BioMed Central will be the most significant development for disseminating the results of biomedical research in our lifetime. "

Sir Paul Nurse, Cancer Research UK

Your research papers will be:

- available free of charge to the entire biomedical community

- peer reviewed and published immediately upon acceptance

- cited in PubMed and archived on PubMed Centra

- yours - you keep the copyright 